\title{
HIDROLOŠKI I KOMUNALNI USLOVI PODRUČJA TUZLE U FUNKCIJI POJAVE KLIZANJA TERENA
}

Nedim Suljić ${ }^{1}$

УДК: 556.1: 624.131.537(497.6Tuzla)

DOI:10.14415/konferencijaGFS 2015.076

Rezime: Tuzla ima karakteristike umjerene kontinentalne klime sa specifičnostima lokalnog reljefa. Na području Tuzle u periodu od 2007. godine do 2014. godine registrovano je preko 2200 klizišta. Najveći broj registrovanih klizišta bio je u junu 2010. godine i u maju 2014. godine. U maju 2014. godine je registrovano nešto više od 1900 klizišta. Klizišta su ugrozila veliki broj putnih komunikacija. U junu 2010. godine $i$ maju 2014. godine porušeno je ili znatno oštećeno oko 700 stambenih individualnih objekata.

Ovaj rad analizira uticaj $i$ značaj hidroloških parametara $i$ uticaj neriješene odvodnje površinskih voda sa padinskih dijelova grada Tuzle sa aspekta pojave klizišta. Rad daje analizu direktne zavisnosti i veze količine padavina, nepostojanja oborinske kanalizacije ili neadekvatne oborinske kanalizacije sa padinskih dijelova grada u odnosu na pojavu nestabilnosti padina, a sve kroz primjere specifičnih klizišta u gradu Tuzli.

Ključne reči: padavine, temperatura vazduha, neriješena odvodnja, klizišta.

\section{UVOD}

Grad Tuzla se nalazi u sjeveroistočnom dijelu Bosne i Hercegovine i predstavlja značajan rudarski, industrijski i univerzitetski centar zemlje. Na području grada Tuzle postoji dobro razvijena putna mreža sa magistralnim saobraćajnicama Tuzla-Orašje, Tuzla-Bijeljina, Tuzla-Doboj i Tuzla-Brčko. Površina područja Tuzle iznosi oko 303 $\mathrm{km}^{2}$ sa nadmorskom visinom od $231 \mathrm{~m} . \mathrm{nm}$.

U geološkom pogledu može se svrstati u kontaktnu zonu Dinarida i Panonske nizije. Geomorfološke karakteristike Tuzle su složenog karaktera što je posljedica geološke građe, strukturno-tektonskih karakteristika i antropogenih aktivnosti. Na području Tuzle najzastupljeniji je padinski dio reljefa, dok u morfološkom pogledu padine područja Tuzle imaju razne oblike, veličine i nagibe. Antropogeni ili vještački reljef grada Tuzle je nastao usljed dejstva i rada ljudskih aktivnosti kod gradnje vještačkih nasipa, deponija pepela i šljake, usjeka na padinama prilikom gradnje individualnih stambenih objekata i slično.

Hidrografska mreža na području Tuzle je dobro razvijena i pripada istočnom dijelu slivnog područja rijeke Spreče sa njenom pritokom rijekom Jalom. Takođe, značajni su i

\footnotetext{
${ }^{1}$ Prof.dr.sc. Nedim Suljić, Univerzitet u Tuzli, Rudarsko-geološko-građevinski fakultet, Univerzitetska 2, Tuzla, Bosna i Hercegovina, tel. 0038735320 550, e - mail: nedim.suljic@untz.ba
} 
International conference

Contemporary achievements in civil engineering 24. April 2015. Subotica, SERBIA

manji vodotoci kao što je rijeka Solina, te manji bujični vodotoci (Dobrinjska rijeka, Mramorski potok, Dokanjski potok itd). Na jednom dijelu područja Tuzle nalazi se i najveća hidroakumulacija u Bosni i Hercegovini (hidroakumulacija Modrac, izgrađena 1964. godine). Poseban značaj i specifičnost grada Tuzle čine i tri slana „Panonska jezera”, po kojima je Tuzla postala prepoznatljiva i van granica bivše Jugoslavije.

\section{KARAKTERISTIKE HIDROMETEOROLOŠKIH PARAMETARA}

Područje grada Tuzle ima osobenosti umjereno kontinentalne klime, što je određeno lokalnim reljefom i opštim položajem u odnosu na centralni planinski masiv i Panonsku niziju. Prosječna godišnja temperatura u zadnjih 50 -ak godina se kreće između $9,0^{\circ} \mathrm{C}$ i $10,6^{\circ} \mathrm{C}$, dok je prosječna suma padavina oko $900 \mathrm{l} / \mathrm{m}^{2}$. U ovom tipu klime relativna vlažnost i oblačnost imaju ljetni minimum i zimski maksimum.

$\mathrm{Na}$ osnovu analiza vrijednosti pojedinih hidrometeoroloških parametara kao i analize vremenskog pojavljivanja klizanja terena na području grada Tuzle, došlo se do podatka o direktnoj povezanosti količine padavina i naglog topljenja snijega sa aktiviranjem novih i reaktiviranjem starih klizišta. U skladu sa sve izraženijim klimatskim promjenama na području regiona vidljivo je povećanje broja klizišta na području Tuzle, naročito $u$ periodu od 2007. godine do 2011. godine, a posebno u maju 2014. godine.

Na području Tuzle nema izraženog sušnog perioda. Maksimum padavina je početkom ljeta, dok je minimum padavina u januaru, februaru i oktobru. Kišni pljuskovi tokom ljetnih mjeseci predstavljaju jednu od karakteristika ovog područja.

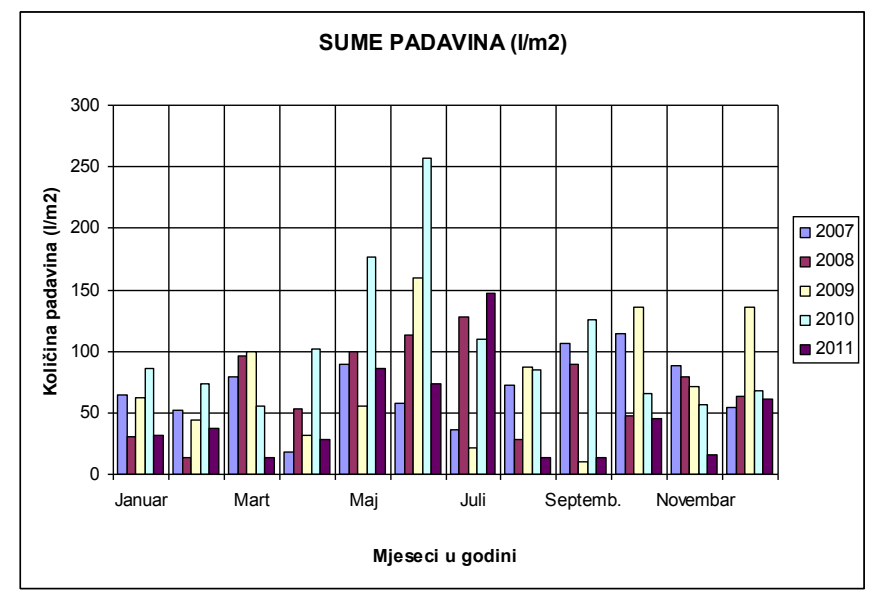

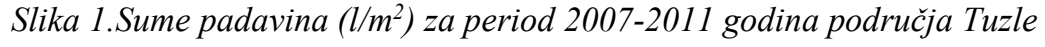

Sa slike 1 uočljivo je da su najveće količine padavina bile u toku 2010. godine, sa količinom padavina od $257,0 \mathrm{l} / \mathrm{m}^{2}$ za mjesec juni i $177,0 \mathrm{l} / \mathrm{m}^{2}$ za mjesec maj. Ukupna suma padavina za 2010. godinu je iznosila $1261,0 \mathrm{l} / \mathrm{m}^{2}$ što je znatno veće od višegodišnjeg prosjeka za područje Tuzle koje iznosi $894,31 / \mathrm{m}^{2}$. U periodu od 01 . juna 2010. godine do 10. juna 2010. godine na području Tuzle je registrovano oko 380

\section{4}


klizišta. Ovo pokazuje direktan uticaj obilnih kišnih padavina na pokretanja padinskih dijelova terena u gradskim i prigradskim sredinama.

Analiza vrijednosti srednjih temperatura vazduha za period od 2007. do 2011. godine pri ekstremnim smjenjivanjem sušnih perioda i perioda sa intenzivnim padavinama, daju značajne podatke u funkciji vremenskog pojavljivanja klizišta na području Tuzle.

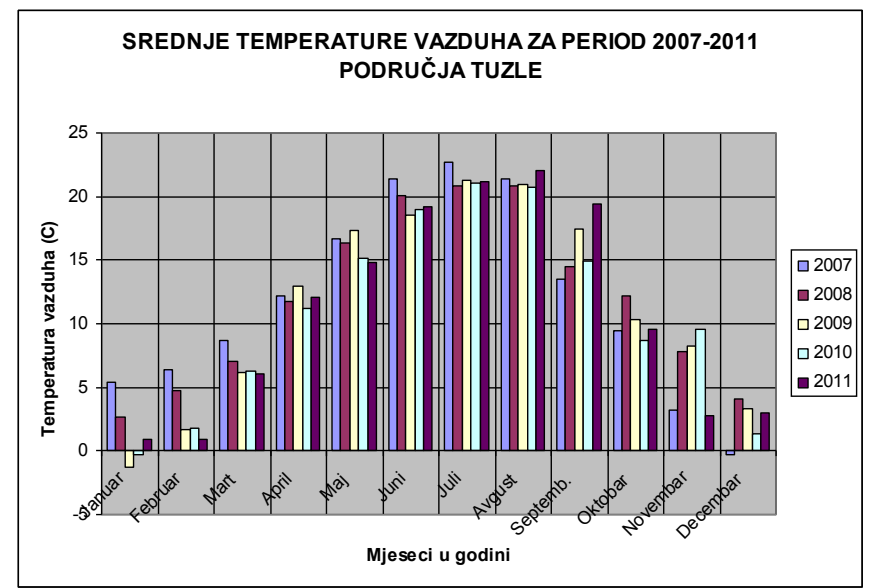

Slika 2.Srednje temperature vazduha $\left({ }^{\circ} \mathrm{C}\right)$ za period 2007-2011 godina područja Tuzle

Srednja temperatura vazduha tokom 2010. godine iznosila je $10,8{ }^{\circ} \mathrm{C}$ što je najniža temperatura za analizirani period, što je imalo direktan uticaj na povećanje padavina, a samim time i aktiviranje klizišta na području Tuzle. Srednja temperatura vazduha u junu 2010. godine iznosila je $19,0{ }^{\circ} \mathrm{C}$ što je gotovo najniža temperatura u ovom mjesecu za analizirani period godina. U maju 2014. godine uslijed dugotrajnih padavina koje su se intenzivirale u svim opštinama na području Tuzlanskog kantona, došlo je do naglog porasta vodostaja u vodotocima.

Za četiri dana ukupno je palo više od $250 \mathrm{l} / \mathrm{m}^{2}$ kiše što je 2,7 puta više u odnosu na prosječnu količinu mjesečnih padavina za mjesec maj, koja za Tuzlu iznosi $92,01 / \mathrm{m}^{2}$. Obilne kišne padavine za kratko vrijeme su uzrokovale dramatičan porast svih vodotoka na području Tuzle. Bujični vodotoci su izazvali plavljenje velikog broja stambenih, poslovnih i infrastrukturnih objekata.

Veliki broj mostova je uništen ili oštećen, veliki broj lokalnih puteva je zatvoren, a zabilježene su teškoće u odvijanju saobraćaja na regionalnim i magistralnim putevima. Ubrzo nakon toga aktivirana su brojna klizišta i odroni zemljišta na području svih 13 opština Tuzlanskog kantona, koja su ugrozila i oštetila izuzetno veliki broj stambenih i industrijskih objekata, magistralnih, regionalnih i lokalnih puteva te drugih infrastrukturnih objekata.

U prvoj dekadi mjeseca maja 2014. godine bile su neuobičajno velike visine padavina za područje Tuzle, dok su u periodu od 14. do 17. maja intenzivirane obilne padavine što je imalo za posljedicu da gotovo cjelokupne bruto padavine budu ujedno i efektivne ili neto padavine, jer je tlo bilo prezasićeno vlagom zbog prethodnih padavina. 
International conference

Contemporary achievements in civil engineering 24. April 2015. Subotica, SERBIA

Cjelokupne padavine su oticale niz sliv što je uzrokovalo pojavu ogromnog broja klizišta u padinskim dijelovima Tuzle.

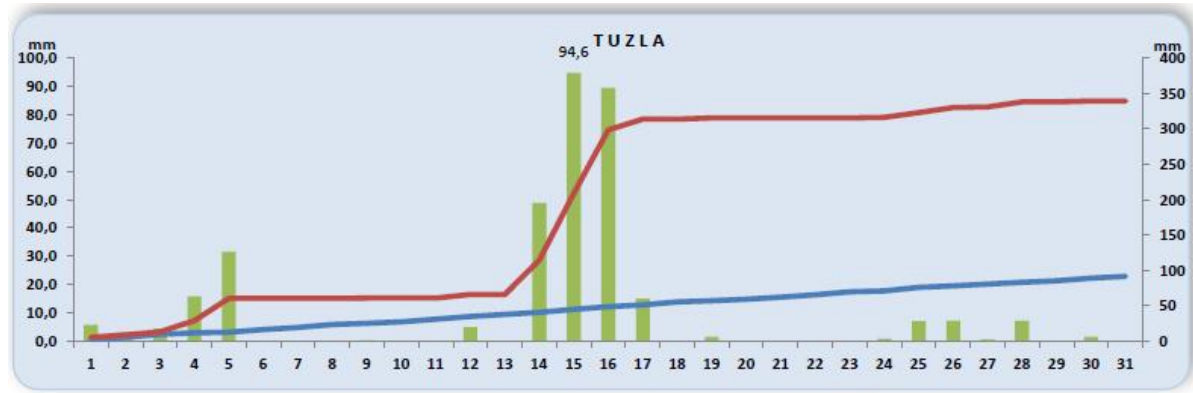

dnevne - prosječne kumulativne_-kumulativne dnevne

Slika 3. Dnevne i kumulativne sume padavina sa prosječnim kumulativnim padavinama u maju 2014. godine za područje Tuzle

\section{KOMUNALNI USLOVI KAO FAKTOR POJAVE KLIZIŠTA}

Kanalizaciona mreža grada Tuzla izgrađena 1912. godine obuhvatila je površinu od cca 124 ha, a u narednimm periodima je realizovana mreža na još cca 18 ha. Danas na području Tuzle najveći dio kanalizacione mreže je mješovitog tipa, dok od sredine 80-tih godina prošlog vijeka novoigrađeni dijelovi naselja Stupine, Sjenjak, Zlokovac i Slavinovići izvedeni su sa razdjelnom kanalizacionom mrežom.

Najveći problem predstavljaju padinski dijelovi grada sa individualnim stambenim objektima, gdje gotovo da uopšte nema oborinske kanalizacione mreže ili je ona samo djelimično izvedena. Nepostojanje oborinske kanalizacione mreže predstavlja jedan od osnovnih uzroka pojave velikog broja klizišta tokom 2010. i 2014. godine, kada se bile dugotrajne kiše.
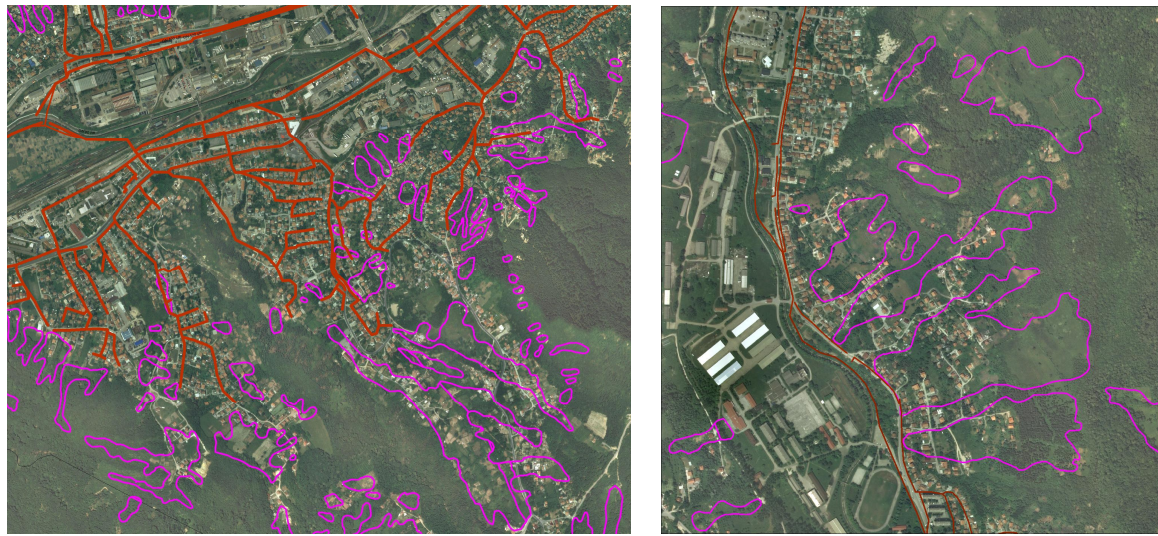

Slika 4. Postojeće stanje kanalizacione mreže na području Mosnika (lijevo) i Badri (desno)

\section{6}


Na slici 4 crvenom linijom prikazana je postojeća kanalizaciona mreža, dok površine ograničene ljubičastom linijom predstavljaju evidentirana klizišta u maju 2014. godine. Na području naselja Mosnik, sa slike 4 (lijevo), može se vidjeti da tamo gdje postoji kanalizaciona mreža (donja trećina padine ovog naselja) nema pojave klizišta, dok u višim dijelovima gdje nije izvedena kanalizaciona mreža uočen je veliki broj klizišta.

Na slici 4 (desno) prikazano je naselje Badre koje nema izvedenu oborinsku kanalizaciju i koje je gotovo cijelo pod klizištima.

Poseban problem predstavlja (ne)mogućnost rješavanja oborinske kanalizacije za naselje Badre, pošto glavni kolektor koji prolazi Solinskom cestom je prečnika DN250mm i ne može prihvatiti oborinske vode sa ovog slivnog područja, prema urađenim hidrološkim i hidrauličkim proračunima.

\section{KLIZIŠTA NA PODRUČJU TUZLE}

Područje grada Tuzle je sigurno i najugroženije pojavama klizišta u Bosni i Hercegovini. Gotovo u svim dijelovima grada postoje registrovana klizišta, a naročito na padinskim gradskim i prigradskim područjima, a naročito u naseljima Badre, Mosnik, Kojšino, Crno Blato i Husino.

Na području Tuzle od početka maja do sredine jula 2014. godine registrovano je 1976 klizišta, koja su srušila 48 stambenih objekata i oštetila 622 stambena objekta.

Osnovni uzrok pojave velikog broja klizišta je neriješena odvodnja oborinskih i dijelom otpadnih voda sa padinskih dijelova područja Tuzle, jer tokom dugotrajnih kiša tlo postaje potpuno zasićeno vodom. Takođe, na pojedinim dijelovima grada ima bespravno izgrađenih objekata što zajedno sa neriješenom odvodnjom čini glavni razlog pojave klizišta.
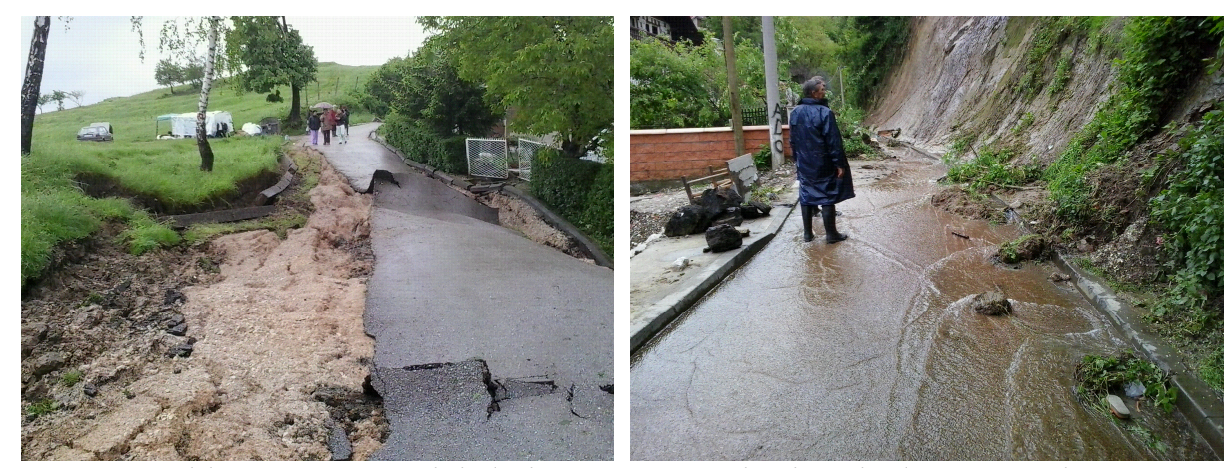

Slika 5. Oštećenja lokalnih puteva na padinskim dijelovima grada 

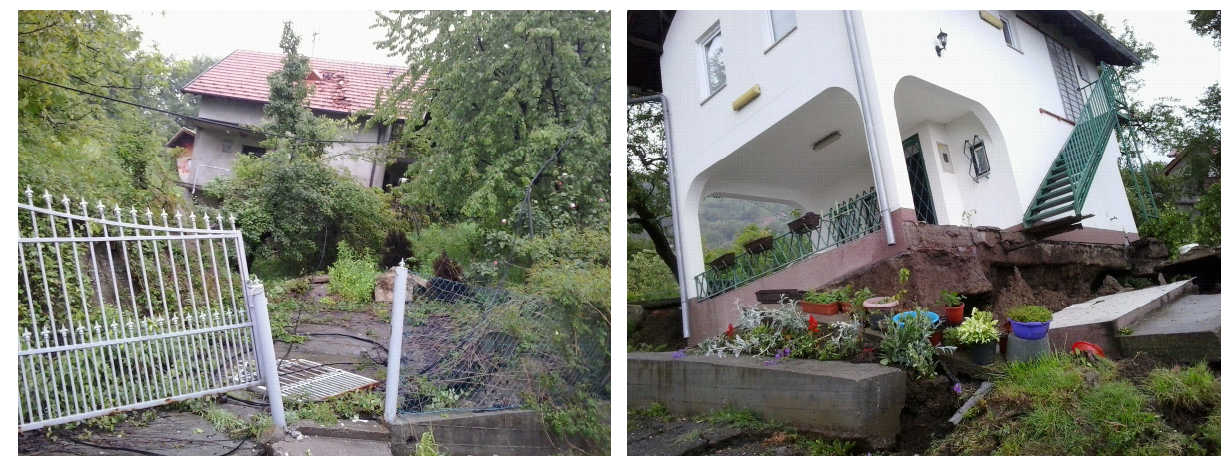

Slika 6. Oštećenja stambenih objekata na padinskim dijelovima grada

\section{ZAKLJUČNA RAZMATRANJA}

Na području Tuzle zadnjih godina vidljivo je povećanje broja klizišta u određenim vremenskim periodima i hidrološkim uslovima. Pojava velikog broja klizišta je obično u maju ili početkom juna mjeseca, jer se tada uglavnom i javljaju višednevne kiše, što uz neadekvatnu ili neriješenu oborinsku kanalizaciju predstavlja glavni uzrok nastanka klizanja terena. Takođe, tome doprinose i nelagalno izgrađeni stambeni privatni objekti na onim padinskim dijelovima grada gdje nije dopuštena gradnja, zbog ranije eksploatacije soli i nestabilnosti padina terena.

Geološka građa područja Tuzle karakteriše se stijenskim masama različitog sastava koja sa hidrogeološkim uslovima stvara smjenjivanje vodopropusnih i nepropusnih stijena, koje procesima raspadanja postaju prekrivene polupropusnim sedimentima. U okviru tih sedimenata odigravaju se značajni procesi klizišta, slijeganje terena na području grada kao i odroni, što dovodi do zaključka da se površine terena u različitim dijelovima grada drugačije ponašaju u pogledu deformacija i otkidanja materijala.

\section{LITERATURA}

[1] Suljić, N.: Potporne konstrukcije, univerzitetski udžbenik, 2010.

[2] Suljić, N.: Savremeni materijali za izvođenje potpornih konstrukcija, IGK „Planjax“, 2005.

[3] Kantonalna uprava civilne zaštite: Informacija o poplavama i klizištima na području $T K, 2014$.

[4] Čomić, J.: Hidrogeološki i antropogeni uslovi formiranja i stabilizacije klizišta na lokalitetima u Tuzli, magistarski rad, 2012.

[5] Federalni hidrometeorološki zavod BiH: Klimatološka analiza za mjesec maj 2014.

\section{8}


Међународна конференција

Савремена достигнућа у грађевинарству 24. април 2015. Суботица, СРБИЈА

\section{HYDROLOGICAL AND COMMUNAL CONDITIONS TUZLA AREA IN THE FUNCTION PHENOMENA SLIDE OF THE SOIL}

Summary: Tuzla has characteristics of moderate continental climate with the specifics of local relief. On the area of Tuzla in the period from 2007 to 2014 evidented over 2200 landslides. The largest number of registered landslides was in June 2010 and May 2014. In May 2014, was registered just over 1900 landslide. Landslides threaten the large number of road communications. In June 2010 and May 2014, destroyed or significantly damaged about 700 residential individual objects.

This paper analyzes the impact and importance of hydrological parameters and the impact of unresolved drainage of surface waters from the slope parts of the city of Tuzla, from the aspect apperance of landslides. The paper gives an analysis of of direct dependencies and connections rainfall, lack of or inadequate rainfall sewer with slope parts of the city in relation to the occurrence of instability of slopes, and all through the examples of specific landslides in the town of Tuzla.

Keywords: rainfall, air temperature, unresolved drainage, landslides. 